\title{
AN IMPROVED METHOD FOR TOPICAL CEREBRAL COOLING DURING DEEP HYPOTHERMIC CIRCULATORY ARREST
}

Geoffrey K. Lighthall, MD, PhD, Christopher R. Cartwright, MD, and Gordon R. Haddow, MB, ChB, FFA(SA), Stanford, Calif

Hypothermia is used in circulatory arrest to decrease cerebral metabolic rate during a period when oxygen and energy substrate delivery are absent. ${ }^{1,2}$ The incidence of neurologic dysfunction attributed to subtle brain injury resulting from inadequate cerebral protection during circulatory arrest was found to be $19 \%$ in 1 series. ${ }^{3}$ The concept of brain at risk for ischemic injury was elaborated further by Cheung and associates, ${ }^{4}$ who examined inflow-outflow gradients of carbon dioxide, $\mathrm{pH}$, and oxygen content during retrograde cerebral perfusion after deep hypothermic circulatory arrest. They found significant differences in these variables over time, suggesting the presence of ongoing metabolic activity in normal cerebral tissue. Likewise, Griepp and colleagues ${ }^{2}$ have demonstrated decreased jugular venous saturations persisting up to 6 hours after the operation, indicating increased metabolic demands of cerebral tissue relative to oxygen delivery.

An increase in adverse neurologic outcomes with longer arrest periods may be due to warming of the brain, something that may be partially offset by external cooling of the head. Griepp and associates ${ }^{2}$ demonstrated a significantly improved behavioral recovery of pigs undergoing deep hypothermic circulatory arrest if their heads were packed in ice. ${ }^{2}$ Although ice packs are beneficial, our experience has led us to consider their use imperfect. For example, application is not always uniform, pressure points and eye damage may develop, and the ice packs themselves are necessarily bulky and greatly hinder access to the head and invasive lines. Prolonged periods of cooling and circulatory arrest may require replacement of ice packs. We describe here an alternative approach to topical cerebral cooling that is easier to use than ice and that also appears to be a more efficacious means of topical cooling.

Description and methods. Postoperative care of some orthopedic injuries involves fitted devices that use cold water circulation to cool the site of injury. Since their fittings are

From the Department of Anesthesia, Stanford University School of Medicine, Stanford, Calif.

Received for publication March 9, 2000; accepted for publication March 14, 2000.

Address for reprints: Geoffrey K. Lighthall, MD, PhD, Fellow, Critical Care, Stanford University School of Medicine, Department of Anesthesia, 300 Pasteur Dr, H3580, Stanford, CA 94305-5640 (E-mail: geoffL@ leland.stanford.edu).

J Thorac Cardiovasc Surg 2000;120;403-4

Copyright () 2000 by The American Association for Thoracic Surgery

$0022-5223 / 2000 \$ 12.00+0 \quad \mathbf{1 2 / 5 4 / 1 0 7 3 4 4}$

doi:10.1067/mtc.2000.107344

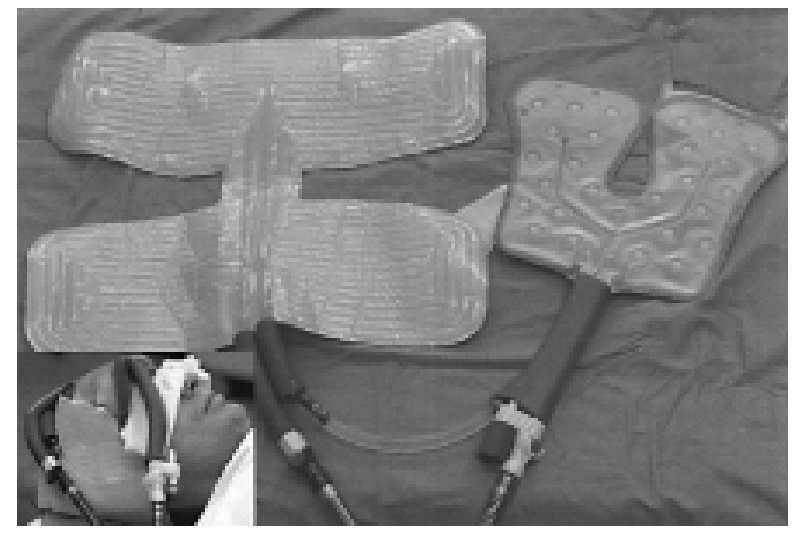

Fig 1. Cryotherapy brace/coolers for an ankle and knee are shown (BREG, Inc, Vista, Calif). Tubing from each was joined by common double-male connectors to produce a single inlet/outlet device, as shown here. Connections are compatible with standard hose couplers from portable and wall-mounted warming/cooling blankets (ie, Blanketrol, Cincinnati Sub-Zero Products, Cincinnati, Ohio). The device is placed on the headrest and folded anteriorly to cover the majority of the head's exposed surfaces (inset). The eyes are covered with gauze to protect against abrasion or pressure damage.

identical to those of the warming/cooling blankets in most operating rooms, we developed a prototype topical head cooler constructed from knee and ankle cooling devices (Fig 1). It is wrapped under and around the head and snapped into the standard warmer/cooler hoses. With such, the blanket temperature control can deliver circulating water as cold as $4^{\circ} \mathrm{C}$. After use in more than 20 patients, we are impressed by the ease of setup and removal afforded by this device, as well as by the consistency of head and neck positioning, lack of interference with invasive lines, and absence of pressure points over the ears and eyes.

We were, however, concerned about whether circulating water at $4^{\circ} \mathrm{C}$ could cool as effectively as topical ice. To address this concern, we compared surface cooling of ice packs with the water jacket cooler in a closed flask simulation. A common volume of water was divided into 2 flasks, which were simultaneously cooled either by our prototype device or by surrounding ice packs. Flask external surface and internal water temperatures were monitored, and temperature gradients within each flask were eliminated by magnetic stir bars. 


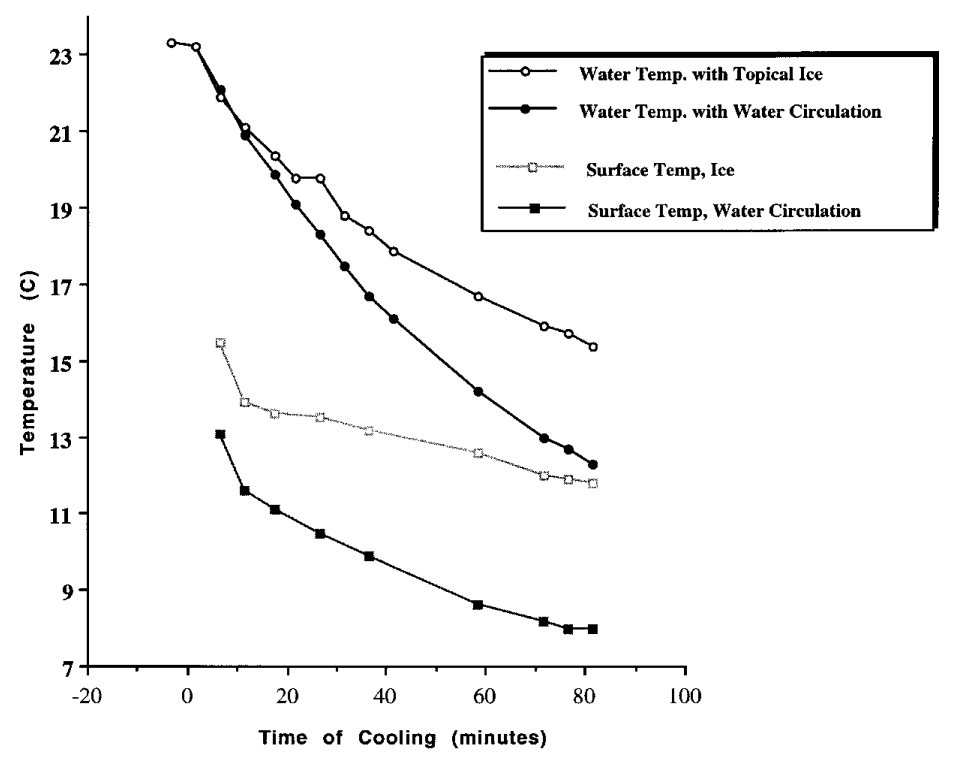

Fig 2. Cooling characteristics of a water-circulating device compared with topical ice packs. A temperature versus time graph of the cooling experiment is shown. The open circles show more rapid cooling with the water circulator than with ice, an effect that produced a $3.5^{\circ} \mathrm{C}$-cooler water bath after 80 minutes. Temperatures recorded between the surface of the water flask and the respective coiling device are shown in the lower two curves: a cooler surface temperature is attained within 5 minutes and maintained throughout cooling with the water-circulating device.

After 10 to 15 minutes, circulating water produced colder temperatures, and after 80 minutes, a $3.5^{\circ} \mathrm{C}$ difference was apparent (Fig 2). Surface temperatures generated by the water circulator were at least $2^{\circ} \mathrm{C}$ lower and did not level off, as did cooling by crushed ice packs. Circulating water prevented heat within the flask from creating a static layer of water that insulates rather than dissipates heat from the water flask. The latter is likely what happened when ice packs were applied to the flask, and it is what probably happens when crushed ice packs are applied to a patient's head. Although our original concern was to show that a water-circulating apparatus works as well as topical ice, we demonstrated in this laboratory model that it delivered an overall greater depth of cooling in a thermodynamically more efficient and stable manner. Likewise, we have shown that the effectiveness of heat transfer with the traditional method of ice packs is lost at a time when adverse neurologic events become more prevalent. The effectiveness of cooling is maintained with circulating cold water applied to the head. The overall efficiency of the device could be further improved by developing a cryotherapy jacket that more closely follows the contours of the head (eg, molding it to fit inside a bathing cap). Further research evaluating main- tenance of cooling temperatures and any regional differences in head cooling (if present) are needed to confirm the clinical usefulness of this device.

\section{REFERENCES}

1. Michenfelder JD, Milde JH. The relationship among canine brain temperature, metabolism, and function during hypothermia. Anesthesiology 1991;75:130-6.

2. Griepp RB, Ergin MA, McCullough JN, Nguyen KH, Juvonen T, Chang N, et al. Use of hypothermic circulatory arrest for cerebral protection during aortic surgery. J Card Surg 1997;12:312-21.

3. Reich DL, Uysal S, Sliwinski M, Ergin MA, Kahn RA, Konstadt SN, et al. Neuropsychologic outcome after deep hypothermic circulatory arrest in adults. J Thorac Cardiovasc Surg 1999;117:156-63.

4. Cheung AT, Bavaria JE, Pochettino A, Weiss SJ, Barclay DK, Stecker MM. Oxygen delivery during retrograde cerebral perfusion in humans. Anesth Analg 1999;88:8-15.

5. Bellinger DC, Wernovsky G, Rappaport LA, Mayer JE Jr, Castaneda AR, Farrell DM, et al. Cognitive development of children following early repair of transposition of the great arteries using deep hypothermic circulatory arrest. Pediatrics 1991;87:701-7. 